\title{
ENCEPHALOMYELITIS AND THE CLINICAL PATHOLOGIST *
}

\author{
BY
}

\section{J. G. GREENFIELD}

Twenty-one years ago I had the honour of addressing this Association in a short Presidential address and I then chose for my theme the opportunity which clinical pathology gave for studying the natural history of diseases. This old term " natural history" recalls Gilbert White's immortal " Natural History of Selbourne." It distinguishes study by observation of naturally occurring biological phenomena from study by planned experiments and thus well describes the special field of the clinical pathologist. Just as Gilbert White described not only the form and colour of birds but also their habits of feeding, nesting, and migration, so the clinical pathologist studies a disease as a whole, its aetiology, its clinical, biochemical and haematological manifestations, and, finally, in some cases, the changes which it produces in the organs of the body. For many of us this last study has such a special fascination that we tend, as we grow older, to devote ourselves more exclusively to it. But, if in our earlier work, we looked at diseases from the broader point of view of the clinician and clinical pathologist, we shall be less likely to lose sight of these wider aspects when we specialize.

It is in this broad manner that I ask you to consider the natural history of encephalomyelitis.

This group of diseases is fortunately rare in Britain. We owe this partly to our position as an island and partly to our climate, which is seldom warm enough to make our indigenous mosquitoes very active or to encourage other forms of biting insects such as wood ticks. As a result we are almost free from insect-borne forms of encephalitis. The only exception is the occasional human case of louping-ill. The only virus disease of the nervous system which has caused much trouble is poliomyelitis and even this disease seems to be discouraged by our climate and only in rare summers approaches anything like epidemic proportions. When therefore the occasional case of encephalomyelitis turns up it arouses little interest and we may be satisfied with this general diagnosis and make no attempt to trace the type of disease.

\footnotetext{
* Foundation lecture delivered at the 55th general meeting of the
} Association of Clinical Pathologists on September 29, 1955.
In looking at the natural history of any disease we must learn from the past. I should like therefore to say something of my own experience with this group of diseases. This goes back to 1917 when I saw my first two cases of encephalitis lethargica, in a convalescent military camp. I was acting then as a physician, and was very puzzled by the peculiar lethargic, sleepy state of the patients, who one minute appeared to be in deep coma and the next minute were answering questions intelligently and again quickly slipped back into deep sleep. Nowadays neurologists would probably attribute this symptom to lesions in the hypothalamus, but at that time we knew next to nothing about that region of the brain. I made a postmortem examination on one of these cases and found nothing except a congested brain. We had no facilities there for cutting sections, but when the epidemic spread to London I soon had as much material as I could handle.

Several points of interest arose in the examination of the cerebrospinal fluid of this disease.

(1) The striking disparity between the high cell count and normal or only slightly raised protein was emphasized first by the French. In the London cases the cell count was almost always purely lymphocytic, but in the short Sheffield epidemic of 1923, which reached its peak after the disease had almost disappeared from London, polymorphonuclear leucocytes were common in the cerebrospinal fluid, in which they might form over $40 \%$ of the cells, as well as in the cerebral lesions.

(2) The French also found in the cerebrospinal fluid abnormally high glucose percentages, such as $100 \mathrm{mg}$. per $100 \mathrm{ml}$. or more. I never satisfied myself that this was constant or, when present, significant. At that time the methods in general use for estimating glucose in small amounts of body fluids were crude and the values they gave were probably higher than the normal, which had been estimated for the cerebrospinal fluid very accurately by Mestrezat in 1912 .

(3) In the earlier years of this epidemic gold sol examinations were rarely carried out on the cerebrospinal fluid, but those who used this test 
found that it commonly gave positive results. In some of the later cases strong reactions of paretic type were found. I believe that this is fairly common in many forms of encephalitis, especially in subacute cases. The gold sol reaction has a special importance in a subacute form which has recently attracted our interest and of which I shall speak later.

The histology of encephalitis lethargica is described in all the textbooks and I shall refer now only to points which are sometimes omitted from these descriptions.

(1) Von Economo (1931) described under the name of "Neurophthoria" the damage which nerve cells undergo in encephalitis. $\mathrm{He}$ describes

" isolated ganglion cells showing varying degrees of cell degeneration, varying from slight tigrolysis to swelling and hyalinization of the cell protoplasm. shifting of the nucleus to the periphery of the cell, pallor and disappearance of the nucleus, extending to the formation of ghost cells."

These changes in the neuron are found in all forms of virus encephalomyelitis. Einarson (1949), who has studied the changes in nerve cells in poliomyelitis, finds in the early stages "chromatolysis with dissolution and diffuse disappearance of the Nissl bodies" and eccentricity of the nucleus. This goes on to vacuolar breakdown of the cytoplasm

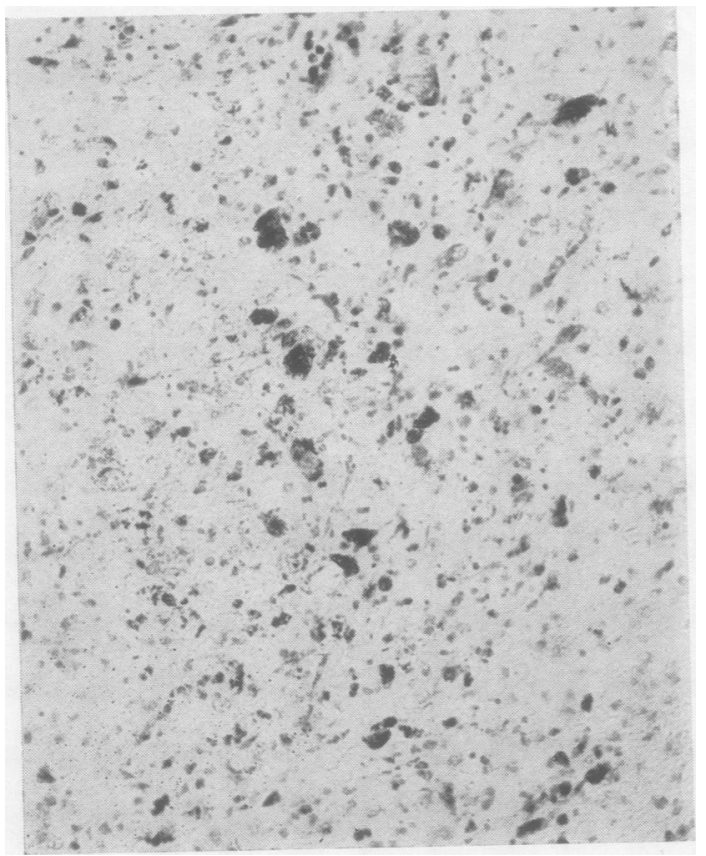

FIG 1-Encephalitis lethargica with a 20-day history: substantia nigra showing severe destruction of pigmented nerve cells with scattering of melanin pigment free in the tissues (toluidin blue).

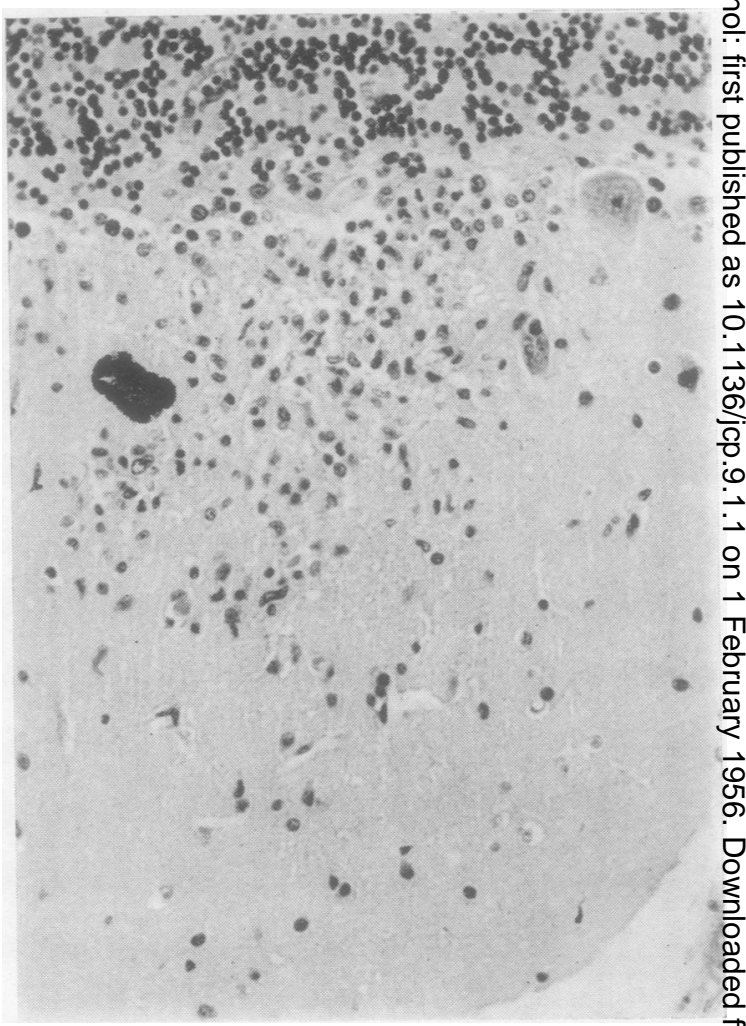

FIG. 2.-Japanese B. encephalitis: cerebellar cortex showing a gliaf shrub in the molecular layer in relation to the dendrites of $\mathfrak{a}$ Purkinje cell which has disappeared. (From a section from the collection of the Armed Forces Institute of Pathology, Washing ton, through the kindness of Dr. W. Haymaker.)

and degenerative shrinkage and disappearance os the nucleus and nuclear membrane.

- The contour of the cell assumes an irregulat ragged appearance, the cytoplasm becomes struc tureless. frequently with relatively increased acido phily, before it disappears altogether as a cell shadow, or is destroyed by macrophages."

The early chromatolysis may, however, be revero sible, and the return of function in limbs paralysed with poliomyelitis is probably due to a recover of this kind.

(2) In encephalitis lethargica, in cases dying the acute stages as well as in cases of post-encephe litic Parkinsonism, disappearance of cells of the substantia nigra is shown by the relatively indestructible melanin granules which are left fre in the tissues (Fig. 1). Or a ring or nodule क्ष phagocytes may be the only evidence that nerge cells are destroyed. In the cerebellar cortex Japanese B. and Russian spring-summer enceph litis, and sometimes in poliomyelitis, loss of 


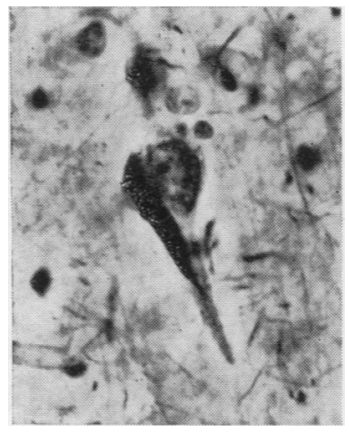

Fig. 3.- "Subacute sclerosing leucoencephalitis" in a girl of 20: cortical nerve cell showing Alzheimer'sfibrillary change. (Case reported by Dr. J. A. N. Corsellis.) (Bielschowsky's silver method.)

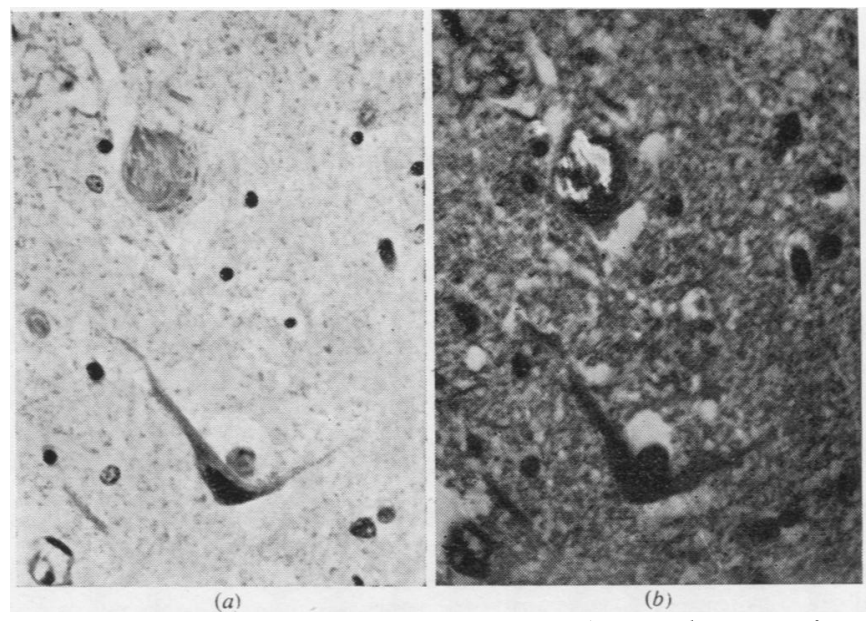

Fig. 4.-Post-encephalitic Parkinsonism: nerve cells from the locus coeruleus stained by congo red. The upper nerve cell has undergone fibrillary change (a), which gives birefringence under crossed Nicol prisms (b).
Purkinje cells may be assumed from the collections of microglial phagocytes which are spread along the remains of dendrites in the molecular layer, an appearance which German writers call " glial shrubs" (Fig. 2).

(3) I have mentioned the loss of cells in the substantia nigra in post-encephalitic Parkinsonism. What is less familiar is that some of the remaining cells, both there and in the locus coeruleus, show fibrillary tangles or whorls similar to those found in Alzheimer's disease (Fig. 3). Hallervorden (1933, 1935), von Braunmühl (1949), and BeheimSchwarzbach (1952), as well as Dr. Bosanquet and myself (Greenfield and Bosanquet, 1953), have found this change very constantly in post-encephalitic Parkinsonism. It may occur in quite young subjects. One of Hallervorden's cases was in a girl of 11 years. Divry (1934) showed that this change is associated with the staining reactions and optical properties of amyloid, but there is no generalized amyloidosis (Fig. 4a and b). Malamud, Haymaker, and Pinkerton (1950) and Corsellis (1951) have found a similar change in cortical nerve cells in children who have survived subacute inclusion encephalitis for some years.

It is still doubtful whether the delay, often of many years, between the attack of encephalitis lethargica and the appearance of Parkinsonism is due to the survival of the presumed virus in the tissues of the brain or to a progressive degeneration and eventual death of nerve cells which were damaged during the acute stages of the disease. The latter suggestion is supported by some obser- vations on cerebral trauma as well as by the neurofibrillary changes which I have already mentioned. This appears to be a very slow form of degeneration, as it has not yet been observed in any of the earlier stages of encephalitis, even in patients with subacute inclusion encephalitis who survive for about a year. The cases of progressive amyotrophy, which occasionally follow encephalitis of the lethargica type as well as poliomyelitis, may be interpreted in either fashion. These are certainly rare, but some cases were reported in the early years from France and Denmark, and Matthews and I (Greenfield and Matthews, 1954) reported two cases recently. In these there was the association of adverse eye movements or oculogyric crises, and Parkinsonism-a syndrome considered to be pathognomonic of encephalitis lethargica-with wasting of the musculature of the upper limbs. Our post-mortem case showed none of the tract degenerations in the cord that occur in amyotrophic lateral sclerosis.

At present we know very little about the metabolism of nerve cells, but it seems possible that viruses may sometimes damage them in such a way that, although they are not immediately destroyed, their normal span of life is greatly reduced. Unfortunately no satisfactory transmission of the virus of encephalitis lethargica to animals was ever achieved, nor has any virus definitely been shown to be the cause of subacute inclusion encephalitis, but this change in nerve cells is similar to that produced by Achucarro (1910) with rabies virus in rabbits. 


\section{Post-infectious Encephalitis}

Encephalitis lethargica had scarcely disappeared when post-vaccinial encephalomyelitis began to cause great anxiety to Ministries of Health, especially in England and Holland. Why it appeared then, almost for the first time, is still in doubt, but the type and strength of vaccine in use at that time may have been to blame. As James McIntosh pointed out, the original Jennerian vaccine, derived from milkmaids who had become infected from cows in the natural course of their work, disappeared very early, and until the present century variola virus, modified by passage through calves, was always used. Sometime in the 1920s the vaccine was again modified by being passed through the brains of rabbits, and this may have altered its virulence. My own experience showed that at the time of the outbreak of post-vaccinial encephalomyelitis the vaccine was so potent that generalized vaccinia or widespread skin eruptions might follow its use in the accepted manner. In fact the epidemic ceased when the strength of the vaccine was reduced and the skin more lightly scarified. Soon after the post-vaccinial cases a similar disease, with lesions of identical type in the brain and spinal cord, came to be recognized as following measles, chickenpox, mumps, and influenza, as well as after mild smallpox. This was by no means the first appearance of post-infectious encephalomyelitis-for example, a very typical

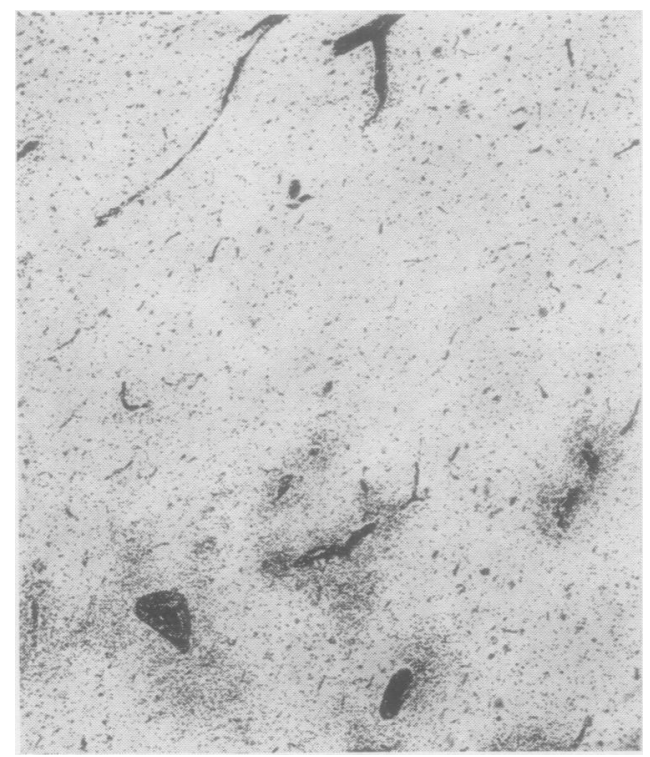

FIG. 5.--Encephalopathy following mumps. (Case of Collins and Armour.) case following mumps had been described by Collins and Armour in 1912 (Fig. 5)-but its? characteristic lesions were recognized then owingo to their similarity to those seen in post-vaccinia cases. The theory that this was an allergic reac $\frac{\bar{c}}{5}$ tion was first put forward by Glanzmann (1927) and has received recent confirmation from then experimental work which has been carried out, especially in the U.S.A., during the last 15 years? Occasional cases following vaccination appeared $\vec{\omega}$ again during the last war when thousands of recruits received their first vaccination agains $\overline{\bar{B}}$ smallpox. In some of these cases, as in some ofo the cases in the earlier epidemic, the spinal cordbore the chief brunt of the attack and the lesions $\overrightarrow{0}$ in it were sometimes severe enough to result in? permanent paraplegia. In other cases the attack was milder and cleared up more or less completely $\frac{\mathbb{O}}{O}$ but often leaving sphincter trouble as a sequeE (Figs. 6 and 7).

During the last war I had the help of Professo James McIntosh and Dr. Selbie of the Middlesex Hospital in an investigation for the Ministry of Health of cases of encephalomyelitis occurring in England and Wales. The Ministry was concerneds about the possible transmission to this country op some of the forms of encephalomyelitis, especially equine encephalomyelitis, which had recently beer? causing epidemics in the United States. Our results have been summarized in the History of the Secon $\bar{B}$ World War (McIntosh, Greenfield, and Selbie 1952), and it is only necessary to say that, apar? from poliomyelitis, the majority of our cases were of the post-infectious type following vaccinationmeasles, and coryza. We had, however, eigh $\mathrm{B}$. other cases of encephalitis of varying acutenes 8 and severity. In none of these cases was the cere bellum involved, nor was there the special incio dence on the substantia nigra which characterize encephalitis lethargica. The workers at the Middlesex Hospital were unable to transmit virus from any of these cases. Since the end of the war I have examined several cases of encephalitio in material sent to me by members of this Associa w tion. These indicate that a form of encephalitio not very different from encephalitis lethargica stiff occurs occasionally in Britain.

\section{Acute Haemorrhagic Leucoencephalitis}

Crawford's recent description (1954) of thi interesting disease is so complete that little need $\mathbb{\Phi}$ to be added. With his summary of the evidenc $\bar{P}$ for its allergic nature $\mathrm{I}$ am in entire agreement The vascular lesion and the intense oedem certainly suggest allergy, though there are usually 


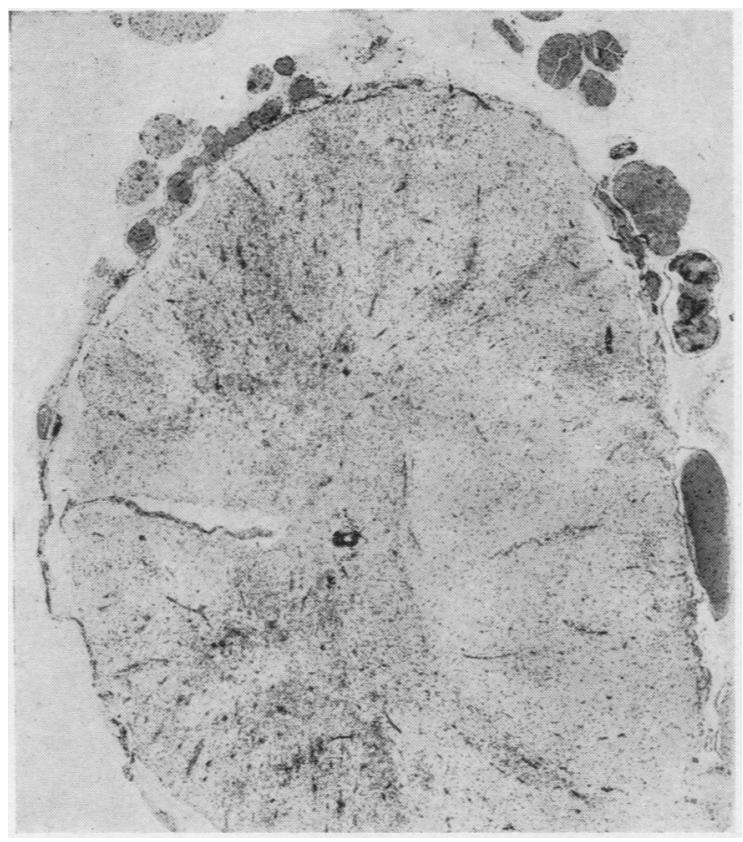

Fig. 6

Fig. 6.-Post-vaccinial myelopathy: spinal cord showing gross lesions in the antero-lateral columns and anterior horns.

FIG. 7.-The same condition as in Fig. 6: higher power view of anterior horn of lumbar enlargement, showing perivenular cell increase without damage to the nerve cells included in this area.

few eosinophils in the exudate. A very interesting question arises here, that of the relationship of acute haemorrhagic leucoencephalitis to postinfectious encephalitis. If both are allergic diseases, and if both may follow influenza, why does their histological picture differ? Or are the differences quantitative rather than qualitative? If so we should expect to find cases with some of the characteristics of either, but so far I have no definite evidence of such transition cases. ${ }^{*}$ It should be noted also that in the experimental production of encephalitis in monkeys, by injection of emulsions of brain with so-called "adjuvants," Wolf, Kabat, and Bezer (1947) found that during the first few days

" polymorphonuclear neutrophiles, occasional eosinophiles and sometimes fibrin were present in the walls of the vessels, their perivascular spaces and in the perivascular parenchyma. This infiltration was associated with congestion, oedema, and occasional fresh perivascular haemorrhages."

These authors comment on the similarity of these appearances to those seen in acute haemorrhagic leucoencephalitis and suggest " that acute haemorrhagic leucoencephalitis may be an acute

* Cases of this kind have recently been reported by Russell (1955).

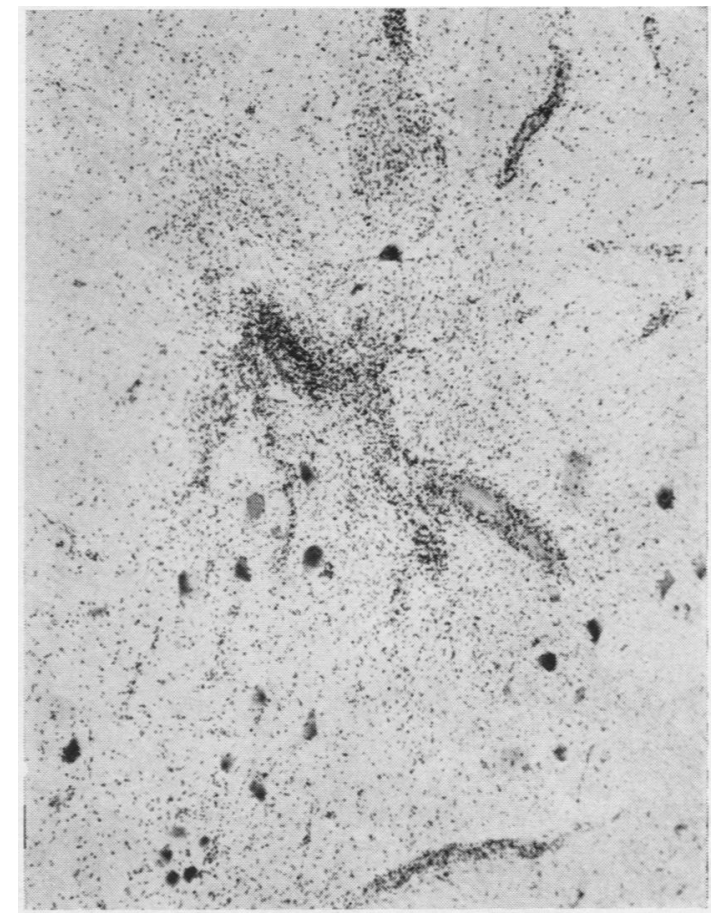

Fig. 7

and violent form of disseminated encephalomyelitis." This similarity has been lost sight of by many who have experimented only with guineapigs, in which the lesions are less acute.

As Crawford has pointed out, these cases are considerably less rare than the number published would suggest, but fortunately they are not common. To the clinical pathologist they present a special problem, as the high polymorphonuclear count both in the blood and in cerebrospinal fluid may well suggest the diagnosis of cerebral abscess. In fact I do not see any escape from this diagnosis in cases with a hemiplegic onset, except perhaps that so acute a clinical course is unusual in cases of abscess.

\section{Subacute Inclusion Body Encephalitis}

At the end of the war I became specially interested in a form of encephalomyelitis which was first, and very well, described by Dawson in the United States in 1933 under the name of " a subacute form of lethargic encephalitis." He described a second case in the following year. He tried to pass the disease to several different kinds of animals but without success; and many similar 


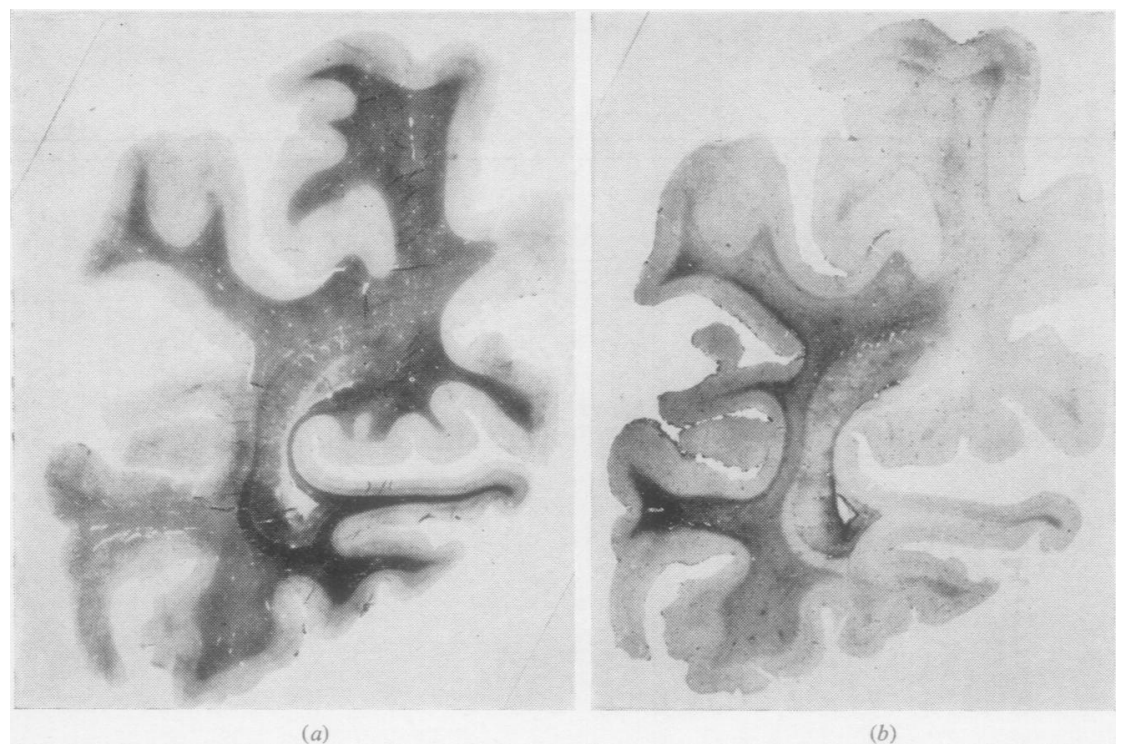

Fig. 8.- Subacute inclusion $\overparen{\mathbb{D}}$ encephalitis in a girl of 9 ? years (duration of illness eight months): coronal sections through the $\bigcirc$ occipital lobe, stained $(a)$ scharlach R-haemalum, $\vec{\omega}$ (b) Victoria blue for $\mathcal{O}$ neuroglial fibres. The area of slight demyelination in? the external and inferior $c$ parts of the section in $(a)$ is seen as an area of fibrous. gliosis in $(b)$.

attempts have been made since then in Britain with equally negative results. From one case Dr. Weston Hurst did finally succeed in passing herpes simplex virus, but in most of the other cases serological tests for herpes simplex infection have been negative. In Switzerland also a doubtful result of virus passage was obtained. We consider it very questionable, although perhaps still possible, that this disease is due to the herpes virus.

In 1945 van Bogaert in Belgium described the same disease under the name "subacute sclerosing leucoencephalitis." As the name shows, he was more impressed by the tendency of the disease to produce demyelination and neuroglial reaction in the white matter than by its effects on the cortex. There is now no doubt that the disease does produce a slow, rather localized demyelination, most often in the occipital lobes (Figs. 8a and b). This is most obvious in long-standing cases, that is, in those which last for a year or more. In a case published by Foley and Williams (1953), which I examined, the appearances might well have been confused with those of Schilder's disease. This form of encephalitis has a special interest to the clinician, because of the tendency for sudden jerks or sudden losses of tone in the limbs and trunk during the middle stage of the disease. They tend to occur with a regular rhythm, every five to 10 seconds. Sometimes the interval varies; for example, there may be an alternation of seven- and nine-second intervals or there may be apparently longer gaps. The E.E.G. is specially interesting, as complexes of large waves tend to appear with the greatest regularity, usually synchronous with the movements, and the record may continue in the same pattern for hours or days at a time, so long as the patient is awake. These jerks may go on $\overline{0}$ without change for weeks at quite regular intervals $\frac{\mathscr{Q}}{\mathbb{Q}}$ in an unconscious patient.

Another interesting point in this disease is the $\overrightarrow{\overrightarrow{0}}$ cerebrospinal fluid, which is usually normal, or 3 almost so, with the exception of the gold-sol reaction, which is almost always of fairly strong paretic type. The protein chemistry of this reac-응 tion has not, so far as I know, been studied in this:disease, and it would be interesting to know 3 whether the blood showed an excess of $\alpha$ or $\beta$ ㅇํㅇ globulin, or whether this is only present in the cerebrospinal fluid.

The most characteristic histological feature of $\frac{\text { ? }}{\supset}$ these cases is the inclusion bodies in nerve cellso and oligodendroglia. These were first pointed out to me by Professor Dorothy Russell in a case $\odot$ which she examined at Oxford. Soon after that $N$ I examined another very typical case which, unfor-N tunately, I did not see during life. Since then $I_{\sigma}^{\infty}$ have examined the brains of about 16 cases, many of which I saw during life, and from this experience I can say that inclusion bodies, and in fact? all evidences of encephalitis, may be very difficult to find. In one case I examined many sections ofo the brain three times, at intervals of weeks, before I found inclusions. In other cases they have onlyd been present in certain areas of the brain; for $\frac{}{\sigma}$ example, the nuclei pontis in one case contained more than any area of cerebral cortex, though ito 
FIG. $9 a$ and $b$.- Subacute inclusion encephalitis: nerve cells in cerebral cortex showing intranuclear and crescentic cytoplasmic inclusions. The nucleolus is displaced to the nuclear membrane. (Lendrum's phloxin-tartrazin method.)

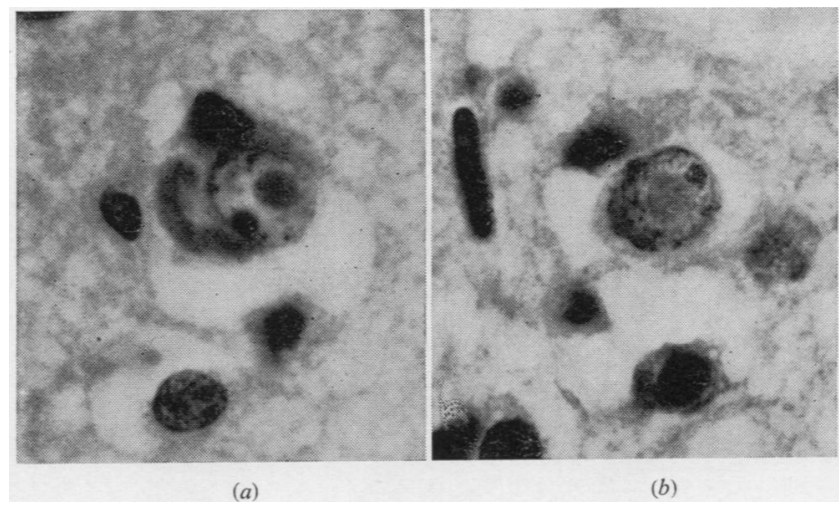

is fair to say that, in this case, the occipital cortex was severely scarred. Similarly many areas of cortex may show very little evidence of encephalitis, and others show only loss of nerve cells and gliosis without inflammatory exudate.

The inclusions in this disease are both intranuclear and intracytoplasmic and, as I have said, the intranuclear inclusions occur both in nerve cells and oligodendroglia. The typical intranuclear inclusion almost fills the nucleus of the cell, and is surrounded by an unstained zone, outside which one can see rather coarse granules of chromatin lying against the nuclear membrane. The nucleolus is pushed to the periphery by the inclusion. The cytoplasm of these cells usually shows a greater or less amount of chromatolysis or it may itself contain acidophilic granular or floccular inclusions. Later the whole nucleus becomes filled by the inclusion, and only a fine line of chromatin granules outlines the nuclear membrane. At this stage the cytoplasm is usually shrunken, but sometimes forms a mass of hyaline acidophilic material which seems to lie beside rather than around the nucleus. These inclusions resemble those of herpes simplex and even more closely those of certain forms of canine distemper (Fig. 9a and b).

On examining the histology of one of these cases in which intranuclear inclusions are difficult to find, there may be little to distinguish it from other forms of encephalitis or from a mild case of general paralysis. But, when the histology is taken along with the clinical symptoms and signs and the electro-encephalogram, the disease becomes separable as an entity, and it appears remarkable that it was not described until 1933. The incidence of the cerebral lesions is also important. In my experience the main areas of incidence are the occipital cortex and white matter, the posterior parts of the thalamus, the nuclei pontis, and the inferior olives. In the two latter areas the only lesions may be clumps of microglial nuclei, socalled " glial stars," but these are rarely absent.

There is, at the present time, a tendency on the continent to distinguish cases, in which the lesions in the white matter are prominent and intranuclear inclusions in nerve cells difficult to find, from those with more evident cortical lesions. In my view this distinction is not justified, since the clinical symptoms are the same in both types of case. As a general rule the cortical lesions are more evident in cases with a short history, and the lesions in the white matter in cases with a longer history, so that the acuteness of the process and the stage of the disease at which the patient dies may be the most important factors in deciding the histological picture.

One of the many interesting features of this disease is its world-wide distribution. It was described first in the United States, then in England and on the continent of Europe, but since then cases have occurred in English children in India. This indicates either a common and very widespread virus such as herpes febrilis (for which as a cause the evidence is still far from clear), or widespread carriage by human migration which is nowadays equally likely. Many of our English cases occurred in or near sea-ports such as London, Bristol, and Southampton, but others have occurred in rural communities. It certainly is a disease which, although rare, merits fuller investigation, especially from the point of view of aetiology.

During the last 15 years a number of cases of acute encephalitis due to herpes simplex virus have been studied. These have occurred both in children and young adults, and in both age groups the disease has run an acute course, fatal in seven to 11 days. The cerebrospinal fluid has shown a very high cell count in which lymphocytes pre- 
dominate or may be the only type of cell. In these cases there is widespread leptomeningitis, and inflammation and necrosis spreads from the cerebral cortex, where it is most severe, to the underlying white matter. It may extend as far down as the pons and medulla, but tends to spare the cerebellum and the spinal cord. Haymaker (1949) describes the areas of inflammatory necrosis as "mushy" to the touch in the fresh state, and microscopically he found many areas in which the necrosis was as complete as in ischaemic foci, but vascular thrombosis was not seen. Intranuclear inclusions were present in these cases both in the nerve cells and in oligodendroglia.

Here I should like to interpose a few remarks about the relation of viruses and intranuclear inclusions to the normal constituents of the nucleus. The nucleus of nerve cells, like all nuclei, plant or animal, contains chromatin or deoxyribonucleic acid and a nucleolus which consists partly of ribonucleic acid and partly of acidophilic protein and is therefore amphophilic. In the larger nerve cells there is a large rounded nucleolus, containing a relatively large amount of ribonucleic acid which, along with the ribonucleic acid in the Nissl granules, is considered by Hydén to be essential for the nutrition of the large cell body and still larger axon. But, as is well known, the nucleolus is still amphophilic, staining with eosin by Mann's eosinmethyl blue method (Levi, 1897). The amount of chromatin or deoxyribonucleic acid in the nucleus is relatively small; in fact in the larger nerve cells there are only very fine granules along the nuclear membrane and a small rounded paranucleolar mass, which Barr and Bertram (1949) have shown to be larger and more definite in the female in cortical

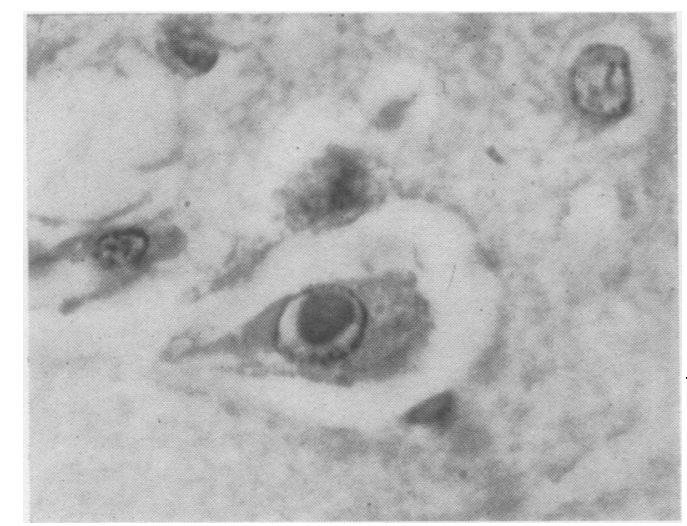

Fig. 10.-Same as in Fig. 9: cortical nerve cell with intranuclear inclusion, showing the nuclear chromatin to be unaffected. (Feulgen-light green.) nerve cells. It is possible to stain either the ribonucleic acid or the acidophilic protein in the nucleolus specifically by different methods, and the Feulgen stain for deoxyribonucleic acid can also be used. Hydén (1947) has studied the nucleoproteins chiefly by the microspectrographic method of Caspersson using ultra-violet light with a wavelength of about $2,570 \AA$ on unstained cells, and by this method he has studied the effects of various kinds of virus on the constituents of the nerve cell. He and Caspersson found that viruses act as parasites on the nucleoprotein of the cell, and multiply chiefly in the nucleus. Rabies virus, like other relatively large viruses such as molluscum contagiosum and verruca simplex, produces an excess of deoxyribonucleic acid in the nucleus. At the same time rabies virus depletes the cytoplasm of the ribonucleic acid, i.e., it produces loss of Nissl granules. Sourander (1953) found that the first effect of rabies virus on nerve cells in the spinal cord of the chick embryo was disappearance of Nissl granules, but later there was also shrinkage of the cytoplasm. He found relatively little change in the nucleus, but Hydén had found in Purkinje cells in rabies a progressive increase of deoxyribonucleic acid in the nucleus. On the other hand, poliomyelitis and louping-ill, which are small viruses, cause an increase of ribonucleic acid which may be shown in the early stages by a swelling of the nucleolus. This seems to apply also to many human cases of encephalitis in which swelling of the nucleolus may be an early change. Disappearance of ribonucleic acid from the cytoplasm also occurs in these forms of encephalitis, leading to the chromatolysis or eosinophilia which has already been described.

The acidophilic intranuclear inclusions of herpes simplex and subacute inclusion encephalitis appear to arise independently of both chromatin and nucleolus. They push both of these structures to the side of the cell, where they may survive unaltered for some time (Fig. 10). Francis and Kurtz (1950) by a differential centrifugalization method showed that nuclei containing intranuclear inclusions of herpes simplex might contain less virus than other constituents of the cell. If, as Hydén has shown, viruses always contain nucleoprotein, it seems probable that these inclusion bodies do not contain virus, but rather consist of waste products formed during the growth of the virus.

It is tempting to correlate the degeneration of the white matter seen in these two diseases with the presence of inclusions in oligodendroglial 
nuclei, since it is probable that the oligodendroglia plays an important part in preserving the nutrition of myelin. But these are by no means the only forms of encephalitis in which the white matter is damaged. In fact it would appear that the more a virus becomes pantropic, that is, the more it tends to damage tissues other than nerve cells, the more tendency there is for involvement of the white matter. In Russian spring-summer or tickborne encephalitis and in equine encephalomyelitis a varying degree of inflammation and damage to the white matter is not uncommon, and in cases surviving western equine encephalomyelitis cystic areas have been seen in the cerebral hemispheres (Noran and Baker, 1943, 1945). These softenings may of course be due to lesions in the vessel walls, since these are common both in western equine and in Russian tick-borne encephalitis. In milder forms they consist of oedema of the vessel walls and swelling of endothelial cells, sometimes associated with thrombosis. When more severe the vessel walls may be invaded by polymorphonuclear leucocytes and become necrotic. However, Weil and Breslich (1942) in western equine encephalomyelitis did not find vascular lesions in softened areas, which they considered were due to more direct effects of the virus.

Viruses also have special tastes in the nerve cells which they attack. This is well known in poliomyelitis, and is well shown in cases of bulbar poliomyelitis, in which the sensory nuclei of the cranial nerves may be surrounded by exudate but their nerve cells remain entirely intact. In fact even the motor nuclei of the cranial nerves usually recover almost completely in such cases, and one rarely sees facial paralysis or atrophy of the tongue as a result of poliomyelitis.

In the cases of encephalitis seen by us during the last war the cerebellum was never involved, but both in Russian spring-summer and the Japanese $B$. form the Purkinje cells may be selectively damaged, as shown by the glial shrub formations in the molecular layer to which $I$ have already referred. In the literature of the early years of the century also a number of cases of encephalitis with transitory cerebellar symptoms were recorded in Britain, but these now seem to be rare.

Encephalomyelitis is not always fatal and may cause only a transient illness with headache, neck stiffness, and sometimes coma. In these cases increase of cells in the cerebrospinal fluid may be the only definite evidence that the nervous system is attacked. These cases are usually classified as benign lymphocytic meningitis, or during an epidemic of poliomyelitis as " non-paralytic polio." They may be due to a great variety of viruses, among which the Armstrong-Lillie virus of lymphocytic choriomeningitis is one of the rarer causes. Some appear to be due to psittacosis and some are associated with atypical pneumonia. Hammon (1949) in the U.S.A. found mumps to be the most common cause. Armstrong (1943), Smadel and Warren (1947) in Washington, and Alm in Gothenburg (1951) have found evidence that the virus of herpes simplex may cause a mild transient form of meningo-encephalitis as well as acute fatal cases. This appears probable enough. Von Magnus (1949) has also brought forward evidence that viruses of the Coxsackie group may be responsible for some such cases and this has been confirmed by Rhodes in Toronto.

Recovery from these forms of encephalitis is usually rapid and complete in older children and adults, and fatal cases are rare, but occasional cases in young children leave mental disability of varying severity as sequelae.

The most urgent problem that cases of benign lymphocytic meningitis present is their differentiation from tuberculous meningitis. For this the intravenous bromide test, recently elaborated by Hunter, Smith, and Taylor (1954), has, in their hands, proved of considerable value.

A question which is exciting some interest on the continent of Europe and in the United States concerns the group of viruses to which the general name encephalomyocarditis or E.M.C. has been given. The distribution of these viruses appears to be almost world-wide. They were first isolated by Smadel and Warren in the Philippines (1947) and independently by Dick and others on the east coast of Africa (Dick, 1949). They have also been found in captive monkeys in Florida. They appear to have been the cause of a mild three-day fever in troops in Manila, and they produced in laboratory workers in Uganda a high fever lasting for four days with complete recovery. Dick and others have shown that a large proportion of the natives on the east coast of Africa have antibodies to viruses of this kind. Saphir (1952) collected three fatal cases in which encephalitis was combined with acute myocarditis, but did not succeed in transmitting the disease to animals. On the continent of Europe also small epidemics in young children have been traced to viruses of the E.M.C. group. Some of these had the symptoms of virus meningitis. In one fatal case death was due to acute myocarditis (Koch, 1950). Certainly in the monkey E.M.C. virus may cause death in this 


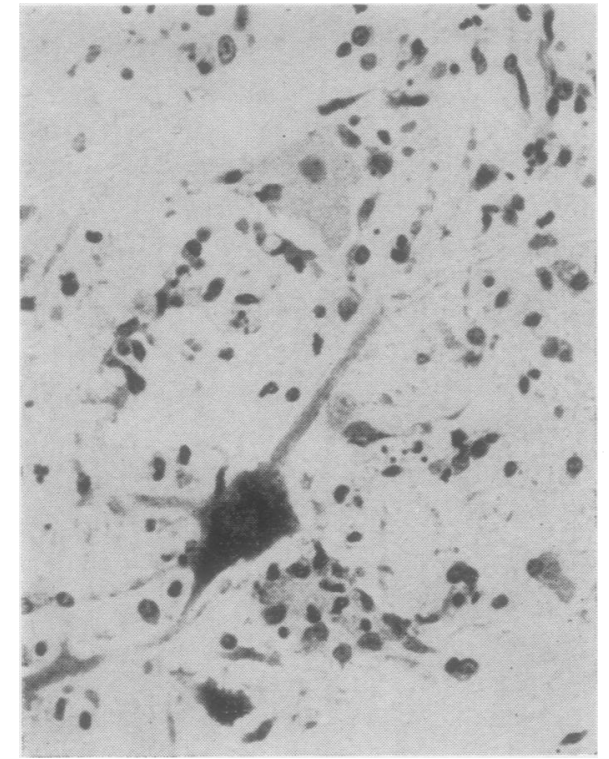

FIG. 11.-Encephalomyocarditis: lumbar cord of a monkey injected with material containing E.M.C. virus. Three anterior horn cells are seen, one undergoing neuronophagy, a second normal and the third appearing as a "ghost cell." (Nissl's stain.)

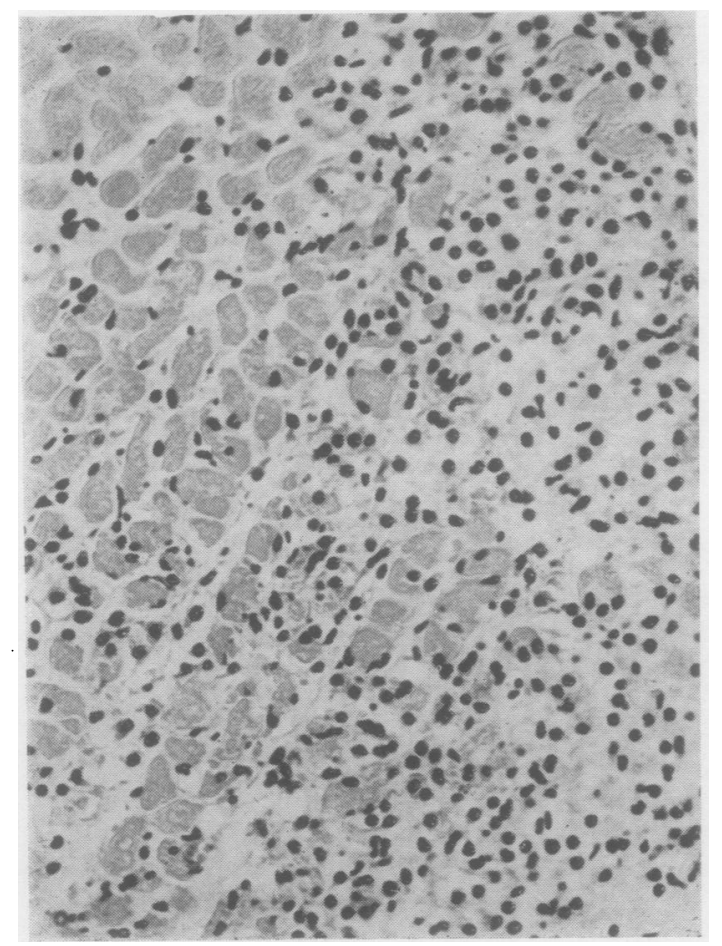

FIG. 12.-Encephalomyocarditis: heart muscle of another monkey which was injected with the same infected material as the monkey from which Fig. 11 was taken, and which died from interstitial myocarditis. (Haematoxylin and eosin.) manner or may produce lesions remarkably like those of poliomyelitis (Figs. 11 and 12).

Another disease which is clinically like mild poliomyelitis has occurred as an epidemic in Iceland, and a number of similar cases have been seen in the north-eastern states of America, especially northern New York State and the neighbouring parts of Canada (White and Burtch, 1954). The virus of this Iceland disease has not yet, so far as I know, been isolated.

The continent of Australia has also been visited by epidemics of encephalitis of recent years, especially during and since the war. In the Murray valley there were a number of cases of a disease indistinguishable from Japanese $B$. encephalitis. The available evidence favours the idea that the virus may have been brought to Australia by migrating birds from neighbouring islands occupied, during the war, by Japanese troops, and that it was spread from birds to other animals and eventually to human beings by mosquitoes or other insect vectors. Many of the forms of mosquito which have been incriminated for the spread of the disease in Japan are found also in Australia. It is to be hoped that this disease, which has in the past produced severe epidemics in Japan with thousands of deaths, has not found a reservoir in the fauna of Australia.

To the morbid anatomist this form of encephalitis is specially interesting, as in some of the more chronic cases the deposition of calcium salts in the brain has been so heavy that it is impossible to cut the brains with a knife. This tendency to calcification of brain tissue in encephalitis, which is seen also in western equine encephalomyelitis and in cytomegalic inclusion encephalitis and toxoplasmosis in infants, provides a nice problem for the biochemist.

In South Africa also encephalitis seems to have been more common of recent years. Geerling (1950) has collected about 100 cases most of which occurred in early summer, that is, November and December, with a death rate of about $15 \%$. They had a somewhat prolonged course with recovery, when it occurred, in one to three months. Parkinsonism was a rather frequent late manifestation and other cases were followed by epilepsy, sometimes combined with Parkinsonism. These cases give a further suggestion that the virus of encephalitis lethargica has not entirely disappeared.

In looking towards the future we may ask ourselves whether we are doing as much as we could or should to study the aetiology of virus infections of the nervous system. Virus laboratories are few and most are understaffed; virologists are not 
therefore likely to be interested in every case of three- or four-day fever in which the cerebrospinal fluid shows a high cell count. We may therefore reserve virus studies for fatal cases. On the other hand, the development of egg-culture and tissue-culture techniques and of complement deviation reactions with viral antigens has brought virology much nearer to the clinical pathologist. Virology is beginning to be considered as a necessary part of laboratory work, not only in public health laboratories but in some of the larger hospitals, especially large children's hospitals. To virologists working in such positions problems are presented in a more intimate, if not so urgent, fashion; they are able to study cases which recover and so to learn something of the commoner and less virulent viruses.

For the clinical pathologist who is not a virologist, it is also scientifically more satisfactory to work alongside a virologist learning his language and getting to understand his technique, than to have him immured in a separate institution. Close association of virologists with clinical pathologists will thus be of value to both, not least in the posing and solution of new problems.

\section{REFERENCES}

Achucarro, N. (1910). Nissl Alzheimer Arbeiten, 3, 143. Alm, L. Afzelius (1951). Acta med. scand., 140, Suppl. 263. Armstrong, C. (1943). Publ. Hlth Rep. (Wash.), 58, 16. Barr, M. L., and Bertram, E. G. (1949). Nature (Lond.), 163, 676. Beheim-Schwarzbach, D. (1952). J. nerv. ment. Dis., 116, 619. Bogaert, L. van (1945). J. Neurol. Neurosurg. Psychiat., 8, 101. Braunmühl, A. von (1949). Arch. Psychiat. Nervenkr., 181, 543.
Collins, J., and Armour, R. G. (1912). Rev. Neurol. Psychiat., 10, 361.

Corsellis, J. A. N. (1951). J. ment. sci., 97, 570.

Crawford, T. (1954). Journal of Clinical Pathology, 7, 1.

Dawson, J. R. (1933). Amer. J. Path., 9, 7.

- (1934). Arch. Neurol. Psychiat. (Chicago), 31, 685.

Dick, G. W. A. (1949). J. Immunol., 62, 375.

Divry, P. (1934). J. belge Neurol. Psychiat., 34, 197.

Economo, C. von (1931). Encephalitis Lethargica. Its Sequelae and Treatment, trans. K. O. Newman. Oxford University Press, London.

Einarson, L. (1949). Acta orthop. scand., 19, 27.

Foley, J., and Williams, D. (1953). Quart. J. Med., 22, 157.

Francis, T., and Kurtz, H. B. (1950). Yale J. Biol. Med., 22, 579.

Geerling, R. (1950). S. Afr. med. J., 24, 339.

Glanzmann, E. (1927). Schweiz. med. Wschr., 8, 145.

Greenfield, J. G., and Bosanquet, F. D. (1953). J. Neurol. Neurosurg. Psychiat., 16, 213.

and Matthews, W. B. (1954). Ibid., 17, 50.

Hallervorden, J. (1933). Klin. Wschr., 12, 692.

- (1935). Dtsch. Z. Nervenheilk., 136, 68.

Hammon, W. McD. (1949). IVe Congres Neurologique International, Paris, 1949. Vol. I. Rapports, p. 94.

Haymaker, W. (1949). J. Neuropath., 8, 132.

Hunter, G., Smith, H. V., and Taylor, L. M. (1954). Biochem. J., $56,588$.

Hydén, H. (1947). Cold Spr. Harb. Symp. quant. Biol., 12, 104.

Koch, F. (1950). $\quad Z$. Kinderheilk, 68, 328.

Levi, G. (1897). Riv. Patol. nerv. ment.. 2, 193, 244.

McIntosh, J., Greenfield, J. G., and Selbie, F. R. (1952). In History of the Second World War, ed. A. S. MacNalty. Medicine and Pathology, p. 533. H.M.S.O., London.

Magnus, H. von (1949). Ugeskr. Lag., 111, 1451.

Malamud, N., Haymaker, W., and Pinkerton, H. (1950). Amer. J. Path., 26, 133.

Mestrezat, W. (1912). Le liquide céphalo-rachidien. Maloine, Paris. Noran, H. H., and Baker, A. B. (1943). Arch. Neurol. Psychiat., (Chicago), 49, 398. (1945). J. Neuropath., 4, 269.

Russell, D. S. (1955). Brain, 78, 369.

Saphir. O. (1952). Circulation, 6, 843.

Smadel, J. E., and Warren, J. (1947). J. clin. Invest., 26, $119 \%$.

Sourander, P. (1953). Acta path. microbiol. scand., Suppl. 95.

Weil, A., and Breslich, P. J. (1942). J. Neuropath., 1, 49.

White, D. N., and Burtch, R. B. (1954). Neurology, 4, 506.

Wolf, A., Kabat, E. A., and Bezer, A. E. (1947). J.'Neuropath., $6,333$. 